\title{
Leg Textiloma
}

\author{
A Case Report
}

\section{Elyazid Mouhsine Raffaele Garofalo Alec Cikes Pierre François Leyvraz}

Department of Orthopaedic Surgery and Traumatology, University Hospital, Lausanne, Switzerland

\section{Key Words}

Foreign body $\cdot$ Soft tissue $\cdot$ Neoplasm

\begin{abstract}
Objective: To report and highlight the potential diagnostic pitfalls and consequences of leg textiloma. Case Report and Intervention: A soft tissue pseudotumor of the left leg diagnosed in a 58-year-old man is described. The lesion was caused by a retained surgical gauze after surgery for varicose veins. The surgical gauze had remained in the subcutaneous tissue for 3 years and led to the formation of a $3-\mathrm{cm}$, well-circumscribed, pseudotumoral foreign body granuloma which appeared like a soft tissue tumor. A surgical intervention was performed and the mass was excised. During the procedure an old surgical gauze was found. The histologic examination revealed that a large foreign body granuloma (pseudotumor) had developed in contact with foreign material birefracting under polarized light (gauze). No sign of malignancy was noted. Conclusion: Although no fatal complications have been described in the musculoskeletal localization, the diagnosis is difficult and costly. According to clinical presentation, a differential diagnosis should be made between a tumoral lesion, such as a sarcoma, or a pseudotumoral lesion, such as a gossypiboma. Focal myositis or infections should also be suspected.
\end{abstract}

\section{Introduction}

Despite the precautions usually taken during routine surgical procedures, the possibility of forgetting surgical material in an operative site is well described in the literature. A surgical gauze left within an operative site (textiloma) is a rare but underestimated iatrogenic event and may also have life-threatening consequences for the patients. It represents $48 \%$ of all claims for retained foreign bodies after a surgical procedure in a 7-year period review [1]. Sometimes it is fortunately found a few years after surgery, but fatal complications are also described in the literature [2]. Standard investigations such as radiology and echography may be adequate for localizations such as the abdominal cavity. However, nontypical localizations, such as soft tissue, tend to require more invasive and costly investigations, as well as costly indemnities [1]. Even computed tomography (CT) and magnetic resonance imaging (MRI) scans do not always give a reliable diagnosis when an old soft tissue foreign body is involved, and only a histological examination can provide a definitive diagnosis in this situation [3, 4].

\section{Case Report}

A 58-year-old man working as a public transportation employee was admitted to our Department of Orthopaedics in February 2000 with an 18-month history of swelling and tethering in the lower third of the left leg that progressively enlarged. The patient

\begin{tabular}{ll}
\hline KARGER & ( ) 2006 S. Karger AG, Basel \\
Fax +4161306 1234 34 & \\
$\begin{array}{l}\text { E-Mail karger@karger.ch } \\
\text { www.karger.com }\end{array}$ & $\begin{array}{l}\text { Accessible online at: } \\
\text { www.karger.com/mpp }\end{array}$
\end{tabular}




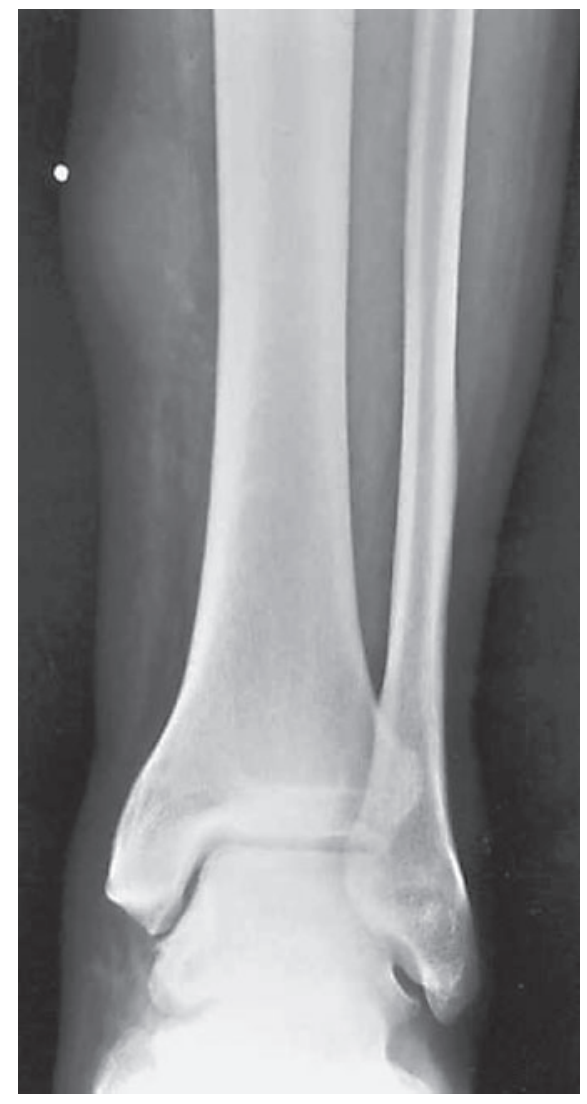

Fig. 1. Frontal view of the distal leg. Medial soft tissue mass (marker). No bone involvement.

did not complain of any pain. Past medical and surgical history included a right inguinal hernia repaired in 1989, stripping of varicose veins in his left leg in 1997 and the presence of gout, as well as a high blood cholesterol level. The physical examination upon admission revealed a patient in good general condition, a normal gait without a limp and the presence of slight edema of the left ankle and distal third of the left calf with ochre dermatitis. A $6 \times$ $4 \mathrm{~cm}$ hard and indolent mass was palpable in the antero-internal side of the distal third of the left leg. This tumoral mass was adherent to the subcutaneous tissues but not to the deep soft tissues. A small surgical scar $(5 \mathrm{~mm})$, due to the surgical procedure for varicose veins appeared on top of the mass. The rest of the examination and laboratory data were normal. A plain X-ray of the left lower extremity and ankle joint highlighting the soft tissue showed a noncalcified tumefaction of the soft tissue with normal underlying bone structures (fig. 1).

Ultrasound examination revealed a solid soft tissue, highly echogenic mass $2 \mathrm{~cm}$ wide and $10 \mathrm{~cm}$ thick. This mass appeared to be surrounded by multiple blood vessels. MRI confirmed the presence of a spindled-shaped mass $2 \mathrm{~cm}$ wide, $6 \mathrm{~cm}$ long and $15 \mathrm{~cm}$ thick, surrounded by fatty subcutaneous tissue. The mass revealed a $\mathrm{T}_{1}$-weighted hyposignal and a $\mathrm{T}_{2}$-weighted hypersignal image with respect to the surrounding fat tissue. The MRI scan also revealed a small white nucleus, which appeared to be a central necro-

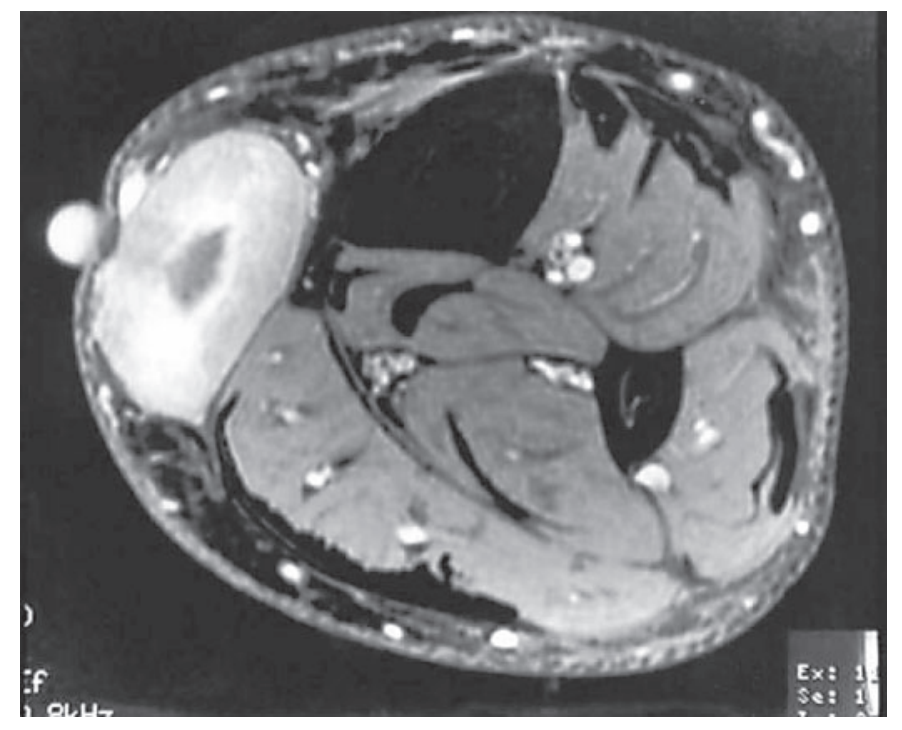

Fig. 2. Transverse $T_{1}$-weighted fat-saturated gadolinium-enhanced MR images. Well-defined soft tissue mass, limited to the subcutaneous tissue, hypointense in $\mathrm{T}_{1}$-weighted fat-saturated MR images, and heterogeneous enhancement after i.v. gadolinium injection. No muscular or bony infiltration.

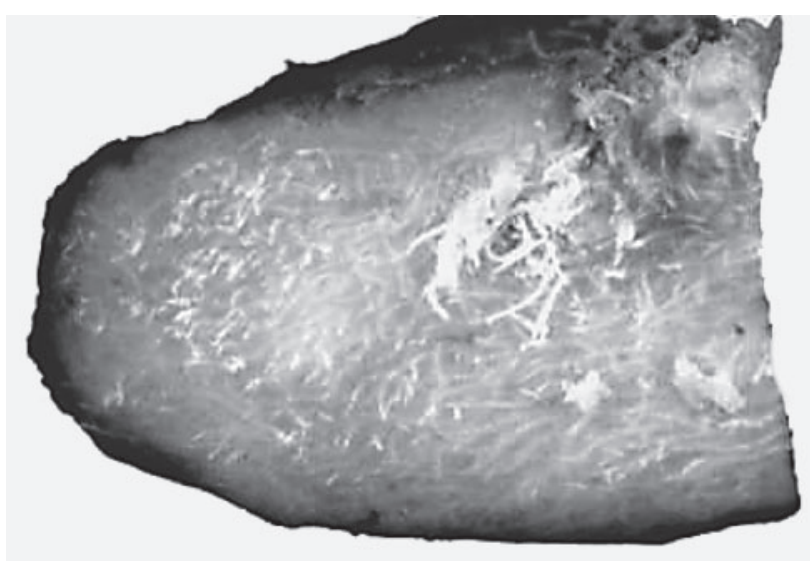

Fig. 3. Gross examination showing the surgical gauze enmeshed in a florid fibroblastic reaction. The gauze was discovered 3 years later.

sis. The mass seemed to be composed of fibrous tissue. After intravenous injection of gadolinium (Gd-DTPA), the mass enhanced and showed a strong vascular supply with large draining veins (fig. 2). The provisional diagnosis was a tumor of mesenchymal origin. The mass was excised. During the procedure, old surgical gauze that had been left since 1997 was found. The histologic examination revealed a large foreign body granuloma (pseudotumor) around material that was birefringent under polarized light (gauze). Features of a benign or malignant tumor were not present (fig. 3). 


\section{Discussion}

The actual incidence of retained gauze is difficult to determine because of the difficulty in obtaining an accurate figure of the occurrence of new cases. Moreover, patients with forgotten intra-abdominal gauze may remain asymptomatic and may be diagnosed only accidentally after several years [1].

In all the studies reviewed, surgical gauze is recognized as the most frequently forgotten surgical material (80\%). The terms textiloma [5], gossypiboma [6] and cottonoid [7] are used in the literature to describe the presence of retained surgical gauze, either of cotton matrix or synthetic fibres, as well as the presence of the surrounding inflammatory tissue. The first to report a retained surgical gauze after abdominal surgery was Wilson in 1884 [4]. In 1940, Crossen and Crossen [cited after ref. 4] performed the most important study reporting on 307 cases. Studies performed on the physiopathology of textiloma described that, after the first $24 \mathrm{~h}$, the fibers cause an inflammatory response becoming an encapsulated fibroblastic granuloma [6], or a nonspecific exudative reaction with abscess or fistulae formation [8].

The clinical presentation of textiloma may be acute or delayed (between 2 months and 2 years). The exudative form usually presents with earlier clinical manifestation because of the possibility of secondary infection and sepsis, or because of the formation of a fistula. The delayed forms consist of tumors which appear after about 2 years, but may also remain latent for many years and can occur up to 16 years later [1]. Textiloma represents a complication of all forms of surgery: abdominal surgery accounts for $52 \%$ of cases, gynecological for $22 \%$, urological and vascular for $10 \%$, and only $6 \%$ of cases in orthopaedic and spinal surgery [2]. It is interesting to note that emergency operations are implicated in only $29 \%$ of the cases whereas $71 \%$ appear after elective procedures [2]. The diagnosis of textiloma starts with surgical history and clinical examination, as well as instrumental diagnosis. The detection and identification of textiloma remains a pitfall [3]. The definitive diagnosis is made only by surgical biopsy, as in our case. Some authors prefer ultrasonography to make the diagnosis. These methods of investigation have demonstrated their effectiveness, but only in abdominal and gynecological procedures [9]. On the other hand, in musculoskeletal procedures, CT and MRI imaging seem to be preferable for diagnosis $[4,10]$. CT imaging may show a whirling pattern with areas of calcification [4], or a spongiform pattern with gas bubbles [3] that appear to be the most characteristic signs for retained surgical gauze.
The problem is that these findings may be absent in about $50 \%$ of cases, and do not demonstrate abscess formation [3]. Therefore, a differential diagnosis with other soft tissue tumors, sometimes partially calcified, may be required. MR imaging has a high resolution for soft tissue and is more sensitive than CT in identifying foreign bodies, but it is not specific. Therefore, even CT and MRI imaging do not confirm the diagnosis, they may suggest the benign nature of the tumor, but the final diagnosis can be performed only by surgical biopsy and histopathologic examination.

The treatment of textiloma is surgical. It consists of removal of the foreign material and surgical debridement. In rare cases a textiloma may be spontaneously expulsed [11]. Prevention remains the best way to avoid textiloma. The most important preventive measure is to keep count of the surgical gauze. A discrepancy in the gauze count was documented in $76 \%$ of 40 cases of textiloma in a study carried out in 1996 [1]. On the other hand, most reported cases of textiloma occurred despite a normal pack count.

The use of radio-opaque surgical gauze, as recommended by Crossen and Crossen in 1940, contributes to reducing the incidence of textiloma, but the marked thread can be misinterpreted as a calcification or as a contrast substance. Moreover, some studies demonstrated that the thread marker is visible in case of a small gauze in only $35 \%$ of the cases. In our case, the marked thread was not visible on plain X-rays. If in doubt and when using unmarked wound dressing, an immediate postoperative X-ray can help identify a lost or forgotten surgical object.

Textiloma is a rare but preventable iatrogenic complication, which may lead (for intra-abdominal localization) to a mortality between 7 and 25\% [2]. The legal consequences of textiloma are significant for the surgeon [1].

\section{Conclusion}

Although no fatal complication has yet been described in musculoskeletal localizations, the diagnosis remains difficult and costly. 


\section{References}

-1 Kaiser CW, Friedman S, Spurling KP, Slowick T, Kaiser HA: The retained surgical sponge. Ann Surg 1996;224:79-84.

$>2$ Le Néel JC, De Cussac B, Dupas B, Letessier E, Borde L, Eloufir M, Armstrong O: Textilomes: à propos de 25 cas et revue de la littérature. Chirurgie 1995;120:272-276.

3 Kopka L, Fisher U, Gross AJ, Funke M, Oestmann JW, Grabbe E: CT of retained surgical sponges (textilomas): pitfalls in detection and evaluation. J Comput Assist Tomogr 1996;20: 919-923.
$>4$ Cowin DJ, Powell GJ, Spanier SS, Makley JT, Scarborough MT: Thigh mass in a 73 year old man. Clin Orthop 1999;366:282-285.

5 Bellin M, Hornoy B, Richard F, Davy-Miallou C, Fadel Y, Zaim S, Challier E, Grenier P: Perirenal textiloma: MR and serial CT appearance. Eur Radiol 1998;8:57-59.

$\checkmark 6$ Hadrami J, Rojas M, de Fenoyl O, Kharsa G, Marzelle J, Chotard Y: Pulmonary textiloma revealed by hemoptysis 12 years after thoracotomy. Rev Med Interne 1998;19:826-829.

7 Pompili A: Magnetic resonance imaging of cotton. J Neurosurg 1999;90:179-180.

$>8$ Sitsinskii SA, Mezhbovskii Vlu: The spontaneous closure of external intestinal fistulae occurring as a consequence of the finding of a foreign body in the abdominal cavity (in Russian). Klin Khir 1999;43-44.
9 Zbar AP, Agrawal A, Saess IT, Utidjian MR: Gossypiboma revisited: a case report and review of the literature. J R Coll Surg Edinb 1998;43:417-418.

10 Salzano A, De Rosa A, Borruso G, Giordano G, Gatta G: A case of gossypiboma of the knee: its computed tomographic diagnosis. Radiol Med 2000;99:188-189.

11 Lin TY, Chuang CK, Wong YC, Liao HC: Gossypiboma: migration of retained surgical gauze and spontaneous transurethral protrusion. BJU Int 1999;84:879-880. 